\title{
Effect of adding a psychological intervention to routine care of common mental disorders in a specialized mental healthcare facility in Pakistan: a randomized controlled trial
}

Syed Usman Hamdani ${ }^{1,2,4^{*}+}$, Zill-e- Huma ${ }^{1,2+}$, Aqsa Masood ${ }^{2 \dagger}$, Kaina Zhou ${ }^{3 \dagger}$, Zainab Ahmed ${ }^{4 \dagger}$, Huma Nazir ${ }^{2 \dagger}$, Hania Amin ${ }^{4 \dagger}$, Parveen Akhtar ${ }^{2 \dagger}$, Richard A. Bryant ${ }^{5 \dagger}$, Katie Dawson $^{5 \dagger}$, Mark van Ommeren ${ }^{6 \dagger}$, Duolao Wang ${ }^{3}$, Atif Rahman ${ }^{1}$ and Fareed Aslam Minhas ${ }^{4}$

\begin{abstract}
Background: In many low resource settings, the provision of government mental health care services is limited to specialized psychiatry units in urban hospital care facilities, where the most common treatment for common mental disorders (CMDs) is pharmacotherapy, occasionally with adjunct nonspecific psychological support. We aimed to evaluate the effectiveness of adding a low intensity, psychological intervention, Problem Management Plus (PM+) for CMDs into routine care in a specialized mental health care facility in Pakistan.

Methods: A two arm, single-blind individual randomized controlled trial $(R C T)$ was carried out with adults $(N=192)$, referred for psychological support by psychiatrists. The study participants were randomized (1:1) to PM+ plus Treatment as Usual (TAU) $(n=96)$ or TAU only $(n=96)$. The primary outcomes were symptoms of anxiety and depression, measured by the Hospital Anxiety and Depression Scale (HADS) and functional impairment as measured by WHO Disability Assessment Schedule (WHODAS 2.0) at 20 weeks after baseline.

Results: The analysis was done on intention-to-treat principle. The linear mixed model analysis showed that at 20 weeks after baseline, there was a significant reduction in symptoms of anxiety and depression (mean [SD], 16.23 [8.81] vs 19.79 [7.77]; $\mathrm{AMD},-3.10 ; 95 \% \mathrm{Cl},-0.26$ to -5.76$) ; p=0.03$ and improvement in functioning (mean [SD], 22.94 [9.37] vs 27.37 [8.36]; $\mathrm{AMD},-4.35 ; 95 \% \mathrm{Cl},-1.45$ to -7.24$) ; p=0.004$ in PM + plus TAU versus TAU arm. The follow-up rate was $67 \%$ at primary end-point.
\end{abstract}

Conclusions: Specialized care facilities in LMICs may consider adding brief, evidence-based psychological treatments for CMDs to their routine care.

Trial Registration Australian New Zealand Clinical Trials Registry, ACTRN12616000381482. Registered March 23, 2016. Retrospectively registered, https://www.anzctr.org.au/Default.aspx/ ACTRN12616000381482

\footnotetext{
*Correspondence: syedusmanhamdani@gmail.com

tSyed Usman Hamdani, Zill-e- Huma and Mark van Ommeren contributed equally to this work

${ }^{\dagger}$ Aqsa Masood, Kaina Zhou, Zainab Ahmed, Huma Nazir, Hania Amin,

Parveen Akhtar, Richard A. Bryant and Katie Dawson also contributed

equally to this work

${ }^{1}$ University of Liverpool, Liverpool, UK

Full list of author information is available at the end of the article
}

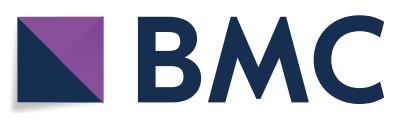

(2021. This article is licensed under a Creative Commons Attribution 4.0 International License, which permits use, sharing adaptation, distribution and reproduction in any medium or format, as long as you give appropriate credit to the original author(s) and the source, provide a link to the Creative Commons licence, and indicate if changes were made. The images or other third party material in this article are included in the article's Creative Commons licence, unless indicated otherwise in a credit line to the material. If material is not included in the article's Creative Commons licence and your intended use is not permitted by statutory regulation or exceeds the permitted use, you will need to obtain permission directly from the copyright holder. To view a copy of this licence, visit http://creativeco mmons.org/licenses/by/4.0/. The Creative Commons Public Domain Dedication waiver (http://creativecommons.org/publicdomain/ zero/1.0/) applies to the data made available in this article, unless otherwise stated in a credit line to the data. 
Keywords: Low intensity psychological intervention, Cognitive behavioral therapy, Specialized mental health facility, Common mental disorders, Depression, Anxiety

\section{Background}

Common mental disorders (CMDs), such as anxiety and depression, are one of the leading causes of disability globally [1]. In low and middle-income countries (LMICs), the treatment gap for CMDs is more than $90 \%$ [2]. Despite the wide-spread recognition of this gap for CMDs in LMICs, the provision of government mental health care services is usually limited to specialized psychiatry units, located in hospital care facilities [3]. Mental health needs are evident in Pakistan, which has been affected by chronic adversity in the form of socio-political instability, economic uncertainty, regional conflict and dislocation. These events have led to increased levels of psychological and social suffering, including a high prevalence of mental disorders in Pakistan $[4,5]$.

A number of psychological intervention manualsmainly based on cognitive behavioral and interpersonal psychotherapy-have been developed and proven effective for treating CMDs in primary health care and community settings in LMICs [6-10] and meta-analyses suggest that such interventions are as effective as pharmacotherapy [11]. The World Health Organization (WHO) recommends that both anti-depressants and psychological interventions should be available to people with depression [12]. A brief, multicomponent behavioral WHO intervention called Problem Management Plus $(\mathrm{PM}+)$ was developed for the management of CMDs in settings affected by adversity [13]. There have been multiple trials of PM + delivered in individual and group formats $[9,10,14]$. However, these studies have focused on evaluating the effectiveness of PM+to reduce CMDs in primary health care and community settings.

The mainstay of treatment for CMDs in many psychiatric units is pharmacotherapy [15], occasionally with adjunct nonspecific psychological support. It is thus valuable to evaluate whether evidence-based psychological interventions can be effectively added in routine specialist health context to reduce the burden of CMDs in LMICs.

\section{Methods}

This study aimed to evaluate the effectiveness of adding $\mathrm{PM}+$ for CMDs to routine care in a specialized mental health care facility in Pakistan. We hypothesized that $\mathrm{PM}+$ in combination with Treatment-as-Usual (TAU) will be superior compared to TAU alone, to reduce the symptoms of depression and anxiety measured with
Hospital Anxiety and Depression Scale (HADS) total score at 20 weeks after baseline.

\section{Design}

We conducted a single-blind individual randomized controlled trial (RCT) to evaluate the effectiveness of $\mathrm{PM}+$ plus Treatment-as-Usual (TAU) versus TAU alone in the treatment of CMDs in patients presenting in the outpatient department of Institute of Psychiatry, Rawalpindi, Pakistan. The study was conducted over the duration of 12 months. Ethical approval of the study was obtained from the Institutional Review and Ethics Board of the Rawalpindi Medical University and Allied Hospitals Rawalpindi (ethical approval certificate number ERC/ RMU/23/05/2015). The full trial protocol is available online [16]. Trial registration: Australian New Zealand Clinical Trials Registry, ACTRN12616000381482. Registered Retrospectively on March 23, 2016.

\section{Study settings}

The participants were recruited from the Institute of Psychiatry (IoP), WHO Collaborating Centre for Mental Health Research and Training, Benazir Bhutto Hospitalthe public sector tertiary care hospital in Rawalpindi, Pakistan. IoP is the hub of mental health policy, services, training and research in Pakistan. It is the specialist referral facility for the patients with mental health problems presenting in the primary and secondary health care facilities in the north of Pakistan. Patient services include in-patients and outpatient services which are led by teams comprising of consultant psychiatrists and psychologists, trainee psychiatrists and psychologists, social workers and interns.

\section{Participants}

The target population for this study was adult (age 18-60 years) outpatient department attendees, referred for psychological support for depression, anxiety and stress related conditions by psychiatrists after clinical evaluation who (a) scored above 2 on a screening questionnaire for psychological distress (General Health Questionnaire-12; GHQ-12); [17, 18] and (b) scored above 16 on a screening questionnaire for functional impairments (WHO Disability Assessment Schedule - WHODAS 2.0) [19]. As PM+ is not suitable for the treatment of severe mental health problems (including psychosis or risk of suicide) [13], participants with imminent risk of suicide, severe mental disorder (e.g. psychotic disorders, 
substance dependence), or severe cognitive impairment (e.g. severe intellectual disability, dementia) as assessed by psychiatrists, were excluded from the study.

\section{Interventions}

\section{Problem Management plus (PM+)}

The WHO PM+intervention (individual version) [13] is based on established principles of problem solving and behavioral techniques and is delivered in five weekly face-to-face sessions administered on an individual basis. The average duration of each session is $90 \mathrm{~min}$. The two key features of WHO PM + program are (a) the program takes a task-shifting approach where non-specialists (workers without a professional license specific for mental health care such as, in Pakistan, psychology graduates, nurses and community volunteers) can deliver this program to adults experiencing common mental health problems (e.g. anxiety, stress, depression and grief) and (b) it is trans-diagnostic-it addresses a range of symptoms for common mental disorders and does not require an expert diagnosis of condition to qualify treatment. $\mathrm{PM}+$ providers in this study had a master's degree (16 years of education) in psychology and received eight days training in $\mathrm{PM}+$ by the master trainer followed by fortnightly supervision meetings with the master trainer.

\section{Treatment-as-Usual (TAU)}

Treatment-as-usual in the outpatient department consists of an initial assessment by trainee psychiatrists followed by an expert consultation on the case by consultant psychiatrist. The main stay of treatment is pharmacotherapy and psychological support where needed. A psychological support session comprises of brief semistructured psycho-education sessions for patients with depression and anxiety symptoms and training in anger and stress management strategies such as breathing exercises. A complete record of services received by trial participants in both study arms was obtained using the Client Services Receipt Inventory (CSRI).

\section{Primary outcomes}

The primary outcomes were (a) symptoms of anxiety and depression measured using the Hospital Anxiety and Depression Scale (HADS) [20, 21] and (b) functional impairment as measured by WHODAS 2.0 [22] at 20 weeks after baseline.

a) The HADS is a well-established 14-item scale consisting of two subscales: HADS-A (anxiety, seven items, and scores range from 0-21) and HADS-D (depression, seven items, scores range from 0-21), where higher scores indicate more anxiety and/or depression. In our study, we used a previously validated Urdu version of HADS [20].

b) Functional impairment was assessed using the 12-item WHO Disability Assessment Schedule (WHODAS 2.0) [22]. WHODAS 2.0 assesses participants' health-related difficulties in the level of functioning in six domains of life (understanding and communicating; moving and getting around; attending to one's hygiene, dressing, eating and staying alone; interacting with other people; domestic responsibilities, leisure, work and school and joining in community activities, participating in society) over the past 30 days. WHODAS 2.0 has been extensively used in different populations and health conditions including mental health and established itself as gold standard to measure functioning [23].

All the study tools were administered in local (i.e. Urdu) language and have been previously used in the similar settings of Pakistan [9, 10, 24].

An independent assessment team, trained in the ethical conduct of research and assessments and blinded to the allocation status of the trial participants, conducted baseline and post-intervention assessments.

\section{Secondary outcomes}

The secondary clinical outcomes included;

The Patient Health Questionnaire-9 (PHQ-9), which is a 9-item instrument measuring presence and severity of depression during the past 2-weeks on a 4-point Likert scale ranging from 'not at all' to 'nearly every day'. The PHQ-9 total severity score ranges from 0 to 27 [25]. Higher scores indicate more severe depression. We used the previously validated Urdu version of PHQ-9 [26, 27].

The 17 item Post Traumatic Stress Symptoms-Checklist (PCL-C) was used to measure DSM-IV based posttraumatic stress disorder symptoms. The participants are asked to rate their responses on a 5-point scale during the past week. The PCL-C has been used previously in Pakistan [28] and found to have good psychometric properties (Mushtaq, unpublished data, 2013). In the current study, we changed the reporting time of PCL from last month to last week to enhance the sensitivity of tool to detect change at the 3 months' post-intervention.

Psychological profile outcome (PSYCHLOPS) - [29] assesses personally identified problems. It consists of four questions that encompass three domains: problems $(2$ questions), functioning (1 question) and wellbeing (1 question). Participants are asked to give free text responses to the problem and function domains. Responses are scored on an ordinal 6-point scale producing a maximum score of 20 (6 points per domain). The PSYCHLOPs version administered at post-treatment and follow-up also includes an 
overall evaluation question (determining self-rated outcome ranging from 'much better' to 'much worse') in relation to the identified problem. PSYCHLOPS has been validated in primary care populations across several countries [30, 31].

The Multidimensional Scale of Perceived Social Support (MSPSS) [32] aims to measure perceived social support. It includes 12 items which cover three dimensions: support from family, friends and significant other. Each item is rated on a 7-point Likert-scale ( $1=$ very strongly disagree; $7=$ very strongly agree). A total score is calculated by summing the responses of all items (range 12-84) with higher scores indicating higher levels of perceived social support. The MSPSS has been validated in Urdu [33].

Services accessed by participants were recorded using the Client Services Receipt Inventory (CSRI). The CSRI was developed for the collection of data on service utilization and related characteristics of people with mental disorders, as the basis for calculating the costs of care for mental health cost-effectiveness research [34]. It has been previously used in Pakistan and India [34, 35].

\section{Procedure}

Patients who presented at the outpatient department between July 2015 and November 2016 for treatment of CMDs were evaluated by a psychiatrist. After clinical evaluation, if the psychiatrist decided psychological support was indicated, $\mathrm{s} /$ he introduced the study and took verbal consent for participation in the study. Written informed consent was obtained from eligible participants by the study coordinator. Participants were randomized to intervention or control arm on a 1:1 basis using computerized software by an independent researcher. The allocation concealment was ensured by keeping random sequence in sequentially numbered, opaque, sealed envelopes, at the off-site center. The intervention arm participants received a total of five weekly individual sessions of $\mathrm{PM}+$ program by $\mathrm{PM}+$ providers and TAU from the psychiatrists/psychologists. The control arm participant received TAU from the psychiatrist/psychologists at the mental health facility. Post-treatment assessments were carried out at two-time points a) seven-weeks after baseline and b) 20 weeks after baseline. Participants who developed severe psychiatric problems (e.g., psychosis, imminent suicidality) at followup were referred to psychiatrists for specialist care $(n=3)$.

\section{Statistical analysis}

Sample size calculation was based on a multicenter study of culturally-adapted cognitive behavioral therapy (CBT)based intervention conducted in Pakistan that used the
HADS as the primary outcome measure [36]. A twopoint reduction in HADS depression score between the intervention and control arm is considered to be clinically relevant [36]. With $p<0.05$ and $90 \%$ power, a total of 96 participants were needed. Accounting for an expected drop-out rate of $50 \%$, the total sample size was 192 participants, who were equally randomized to $\mathrm{PM}+(\mathrm{n}=96)$ and TAU $(\mathrm{n}=96)$.

The data was analyzed using an Intent-To-Treat (ITT) analysis approach. The primary outcome was summarized using number of participants (n), means and standard deviations (SD). To estimate the treatment effect, a linear mixed model was employed for the primary endpoint analysis, which had treatment, visit, interaction between treatment and visit as fixed effects, baseline measurement of primary endpoint as covariate, and subject as random effects. The mean difference between two treatment arms at each visit/time together with its $95 \%$ confidence interval was derived from the mixed model. Covariate-adjusted mixed model of primary endpoint (20 weeks after baseline) was also performed by adding pre-specified covariates at baseline into the above model. Secondary continuous outcomes were analyzed in a similar way. Missing data was treated as missing at random in the mixed model analysis and no imputation of primary and secondary endpoints was made. All analyses were performed using SAS 9.3.

\section{Results}

489 patients were assessed for eligibility. 192 participants, who met the inclusion criteria and provided informed consent were enrolled in the trial and randomly allocated $(1: 1)$ to PM + plus TAU $(n=96)$ and TAU arms $(n=96)$ (Fig. 1). The follow-up rate for primary outcome at the primary endpoint (20 weeks after baseline) was $64.5 \%$ (62 of 96 participants) in the intervention arm and 69.79\% (67 of 96 participants) in the control arm. There were no significant differences between the two arms in demographic characteristics and symptom scores at baseline. The mean $( \pm S D)$ age of the participants was 34.05 $( \pm 10.47)$ years. $68 \%(128 / 192)$ of the participants were females (Table 1).

$58 \%$ of participants attended 3 or more sessions of $\mathrm{PM}+$ intervention. The mean number of intervention sessions attended by trial participants was $2.84( \pm 2.16)$. Each session lasted for an average of $90 \mathrm{~min}$. The quality of intervention delivery was assessed by completing a self-check for each session by the PM+ providers, supported by peer-supervision and fortnightly supervisions with the mental health specialist via Skype. In terms of 


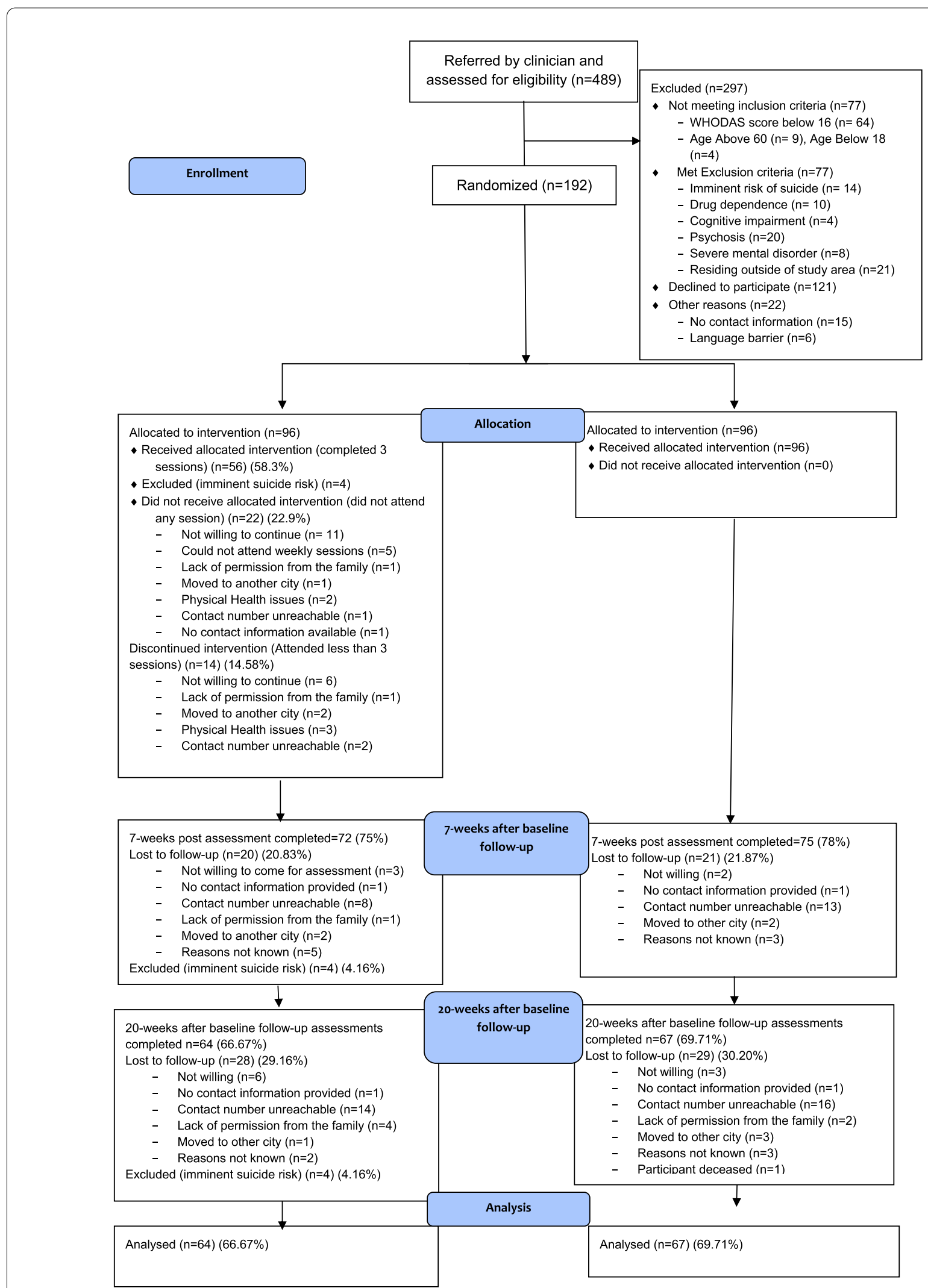

Fig. 1 Participants'flow 
Table 1 Demographic characteristics of the study participants $(n, \%)$

\begin{tabular}{|c|c|c|c|}
\hline Variable & $\begin{array}{l}P M+N(\%) \\
(n=96)\end{array}$ & $\begin{array}{l}\text { TAU N (\%) } \\
(n=96)\end{array}$ & $\begin{array}{l}\text { Total } \\
(\mathrm{N}=192)\end{array}$ \\
\hline Age $($ mean $\pm S D)$ & $33.03 \pm 9.94$ & $35.07 \pm 10.95$ & $34.05 \pm 10.47$ \\
\hline \multicolumn{4}{|l|}{ Gender } \\
\hline Male & $32(33.3)$ & $28(29.2)$ & 60(31.9) \\
\hline Female & $62(64.6)$ & $66(68.8)$ & $128(68)$ \\
\hline \multicolumn{4}{|l|}{ Education } \\
\hline Uneducated & $15(15.6)$ & $25(26)$ & $40(20.8)$ \\
\hline Completed primary (grade 5) & $20(20.8)$ & $12(12.5)$ & $32(16.7)$ \\
\hline Completed middle (grade 8) & $9(9.4)$ & $13(13.5)$ & $22(11.5)$ \\
\hline Completed matriculate (grade 10) & $16(16.7)$ & $14(14.6)$ & $30(15.6)$ \\
\hline Completed College and University (grade 11-16) & $36(37.5)$ & $30(31.3)$ & $66(34.4)$ \\
\hline \multicolumn{4}{|l|}{ Marital status } \\
\hline Never married & $28(29.8)$ & $19(19.8)$ & $47(24.5)$ \\
\hline Currently married & $61(63.5)$ & $69(71.9)$ & $130(67.7)$ \\
\hline Separated & $1(1.0)$ & $2(2.1)$ & $3(1.6)$ \\
\hline Divorced & $3(3.1)$ & $2(2.1)$ & $5(2.6)$ \\
\hline Widowed & $3(3.1)$ & $4(4.2)$ & $7(3.6)$ \\
\hline \multicolumn{4}{|l|}{ Employment status } \\
\hline Employed & $31(32.3)$ & $26(27.1)$ & $57(29.7)$ \\
\hline Not employed & $65(67.7)$ & $70(72.9)$ & $135(70.3)$ \\
\hline \multicolumn{4}{|l|}{ Occupation } \\
\hline Paid work & $24(25.8)$ & $20(21.3)$ & $44(22.9)$ \\
\hline Self-employed & $10(10.8)$ & $8(8.5)$ & $18(9.4)$ \\
\hline Student & $2(2.2)$ & $3(3.2)$ & $5(2.6)$ \\
\hline Keeping house/homemaker & $14(15.1)$ & $18(19.1)$ & $32(16.7)$ \\
\hline Retired & $0(0.0)$ & $2(2.1)$ & $2(1)$ \\
\hline Unemployed (health reasons) & $2(2.2)$ & $1(1.1)$ & $3(1.6)$ \\
\hline Unemployed (other reasons) & $41(44.1)$ & $42(44.7)$ & $83(43.2)$ \\
\hline \multicolumn{4}{|l|}{ Living structure } \\
\hline Nuclear & $49(51.0)$ & $47(49.5)$ & $96(50)$ \\
\hline Joint/extended & $47(49.0)$ & $48(50.5)$ & $95(49.7)$ \\
\hline
\end{tabular}

medication, 36/64 (56\%) participants in PM + and 49/67 (73\%) participants in TAU reported receiving a prescription of psychotropic medicines.(Table 2).

Seven-weeks after baseline, the intervention arm had significantly lower scores on HADS (mean [SD], $16.72[8.44]$ vs 21.0 [7.88]; adjusted mean difference [AMD], 4.35; 95\% CI, 1.71 to 6.99). At 20 weeks after baseline, the intervention arm had significantly lower scores than the control arm on HADS (mean [SD], 16.23 [8.81] vs 19.79 [7.77]; AMD, 3.10; 95\% CI, 0.26 to 5.76). Seven-weeks after baseline, the intervention arm had significantly lower scores on HADS-A (mean [SD], 8.56 [5.00] vs 11.08 [4.90]; AMD, 2.41; 95\% CI, 0.77 to 4.04) and HADS-D (mean [SD], 8.16 [4.17] vs 9.92 [4.37]; AMD, 1.85; 95\% CI, 0.41 to 3.29). At 20 weeks after baseline, the intervention arm had significantly lower scores than the control arm on HADS-A (mean [SD], 8.17 [5.12] vs 10.12 [4.79]; AMD, 1.69 ; 95\% CI, -0.02 to 3.41 ), however, there was no significant difference between two arms on HADS-D (mean [SD], 8.04 [4.89] vs 9.67 [3.94]; AMD, 1.30; 95\% CI, -0.21 to 2.81).(Table 3).

Seven-weeks after baseline, the intervention arm had significantly lower scores on WHODAS 2.0 (mean [SD], 25.20[8.97] vs 28.41 [8.19]; AMD, 3.16 95\% CI, 0.85to 6.38). At 20 weeks after baseline, the difference of WHODAS 2.0 scores between intervention arm and control arm was sustained (mean [SD], 22.94 [9.37] vs 27.37 [8.36]; AMD, 4.35; 95\% CI, 1.45 to 7.24 ).

At 20 weeks after baseline, there was a significant reduction in the level of posttraumatic stress in the intervention arm (mean [SD], 32.93[14.21] compared to the control arm 39.08 [15.75]; AMD, 5.39; 95\% CI, 0.02 
Table 2 Health services utilization across two arms after 20 -weeks after baseline

\begin{tabular}{|c|c|c|}
\hline Health service providers accessed & $\mathrm{PM}+(f)$ & $\operatorname{TAU}(f)$ \\
\hline Psychiatrist & 45 & 49 \\
\hline Specialist doctor & 21 & 33 \\
\hline General doctor & 16 & 11 \\
\hline Pharmacist & 1 & 2 \\
\hline Traditional healer & 2 & 1 \\
\hline Other mental health worker & 2 & - \\
\hline \multicolumn{3}{|l|}{ Number of visits } \\
\hline 3 visits & 8 & 13 \\
\hline 2 visits & 30 & 32 \\
\hline 1 visit & 54 & 65 \\
\hline \multicolumn{3}{|l|}{ Location } \\
\hline Public hospital & 47 & 53 \\
\hline Private hospital & 11 & 6 \\
\hline Local health centre & - & 5 \\
\hline \multicolumn{3}{|l|}{ Reasons for visit } \\
\hline Follow-up visit for treatment of depression or anxiety problems & 50 & 60 \\
\hline Sleep problems & 10 & 13 \\
\hline Acute aggravation of mental health problems & 6 & 13 \\
\hline Other mental health problems e.g. maternal/perinatal mental health condition & 15 & 16 \\
\hline Infectious diseases and injuries & 2 & 2 \\
\hline \multicolumn{3}{|l|}{ Medications } \\
\hline \multicolumn{3}{|l|}{ A. Antidepressants $(n=58)$} \\
\hline SSRIs & 22 & 31 \\
\hline TCAs & 2 & 3 \\
\hline B. Anxiolytics & 8 & 9 \\
\hline C. Mood stabilizers & 2 & 1 \\
\hline D. Anti-psychotics & 2 & 5 \\
\hline E. Multi-vitamins & 8 & 5 \\
\hline F. Analgesics & 4 & 3 \\
\hline G. Others (anti- hypertensive, anti-diabetic, thyroid related) & 6 & 9 \\
\hline Average duration of consultation (in minutes) $M(S D)$; min-max & $7.62( \pm 2.57) ; 3-15$ & $8.85( \pm 3.99) ; 2-20$ \\
\hline Average consultation fee paid (in PKR) M(SD); min-max & 32 ( \pm 129.9): 0-700 & $3.10( \pm 14.79) ; 0-100$ \\
\hline
\end{tabular}

Due to multiplicity of contacts with service providers and treatments received, the table reports frequency of contacts and prescribed treatment; 3 in intervention and 2 participants in TAU were hospitalized during the study

to 10.76). Similarly, there was significant reduction in the symptoms of depressive disorder in the intervention arm (PHQ-9: mean [SD], 7.16[6.23] compared to the control arm 10.29[6.79]; AMD, 2.91; 95\% CI, 0.60 to $5.22)$ at 20 weeks after baseline. However, no significant differences were observed in the scores of PSYCHLOPS (mean[SD], 8.98(5.93) vs 10.62[4.99]; AMD, 1.63; 95\% CI, -0.24 to 3.51 ), and social support (mean[SD], 56.61[17.35] vs 52.57[14.70]; AMD, - 2.24; 95\% CI, -7.90 to 3.42 ) between the two arm at 20 weeks after baseline.

The findings from covariate adjusted analysis showed that, after controlling for the baseline measurements (i.e. age, gender, severity on HADS), there was significant improvement in the intervention arm than TAU arm at both seven and 20 weeks after baseline in the clinical outcome measures.

(Table 4).

\section{Discussion}

The addition of PM+intervention to routine care in a specialist mental health facility in Pakistan led to improvements in symptoms of anxiety, depression, post-traumatic stress, and functioning at seven and 20 weeks after baseline compared to routine care alone. $\mathrm{PM}+$ involves evidence based psychological strategies (including problem solving, stress management, behavioral activation, and strengthening social support) that 
Table 3 Summary statistics and results from mixed-model analysis of primary and secondary outcomes

\begin{tabular}{|c|c|c|c|c|c|c|c|}
\hline \multirow[t]{2}{*}{ Primary and secondary outcomes } & \multirow[t]{2}{*}{ Visit } & \multicolumn{2}{|c|}{$P M+(N=96)$} & \multicolumn{2}{|c|}{ TAU $(\mathrm{N}=96)$} & \multirow{2}{*}{$\begin{array}{l}\text { Difference in least squares } \\
\text { mean }(95 \% \mathrm{Cl})\end{array}$} & \multirow[t]{2}{*}{$P$-value } \\
\hline & & $\mathbf{N}$ & $M(S D)$ & $\mathbf{N}$ & $M(S D)$ & & \\
\hline \multicolumn{8}{|l|}{ Descriptive statistics n, mean (SD) } \\
\hline \multirow[t]{3}{*}{ HADS Anxiety } & Pre-treatment & 95 & $13.44(3.67)$ & 96 & $12.90(4.02)$ & & \\
\hline & Post-treatment & 73 & $8.56(5.00)$ & 73 & $11.08(4.90)$ & $-2.41(-4.04$ to -0.77$)$ & 0.004 \\
\hline & Follow-up & 62 & $8.17(5.12)$ & 67 & $10.12(4.79)$ & $-1.69(-3.41$ to 0.02$)$ & 0.05 \\
\hline \multirow[t]{3}{*}{ HADS Depression } & Pre-treatment & 95 & $12.18(3.99)$ & 96 & $10.80(3.72)$ & & \\
\hline & Post-treatment & 73 & $8.16(4.17)$ & 73 & $9.92(4.37)$ & $-1.85(-3.29$ to -0.41$)$ & 0.01 \\
\hline & Follow-up & 62 & $8.04(4.89)$ & 67 & $9.67(3.94)$ & $-1.30(-2.81$ to 0.21$)$ & 0.09 \\
\hline \multirow[t]{3}{*}{ HADS } & Pre-treatment & 95 & $25.62(6.61)$ & 96 & $23.70(6.07)$ & & \\
\hline & Post-treatment & 73 & $16.72(8.44)$ & 73 & $21.00(7.88)$ & $-4.35(-6.99$ to -1.71$)$ & 0.002 \\
\hline & Follow-up & 62 & $16.23(8.81)$ & 67 & $19.79(7.77)$ & $-3.10(-5.76$ to -0.26$)$ & 0.03 \\
\hline \multirow[t]{3}{*}{ WHODAS } & Pre-treatment & 96 & $33.41(7.17)$ & 96 & $32.77(7.77)$ & & \\
\hline & Post-treatment & 74 & $25.20(8.97)$ & 74 & $28.41(8.19)$ & $-3.16(-6.38$ to -0.85$)$ & 0.01 \\
\hline & Follow-up & 62 & $22.94(9.73)$ & 67 & $27.37(8.36)$ & $-4.35(-7.24$ to -1.45$)$ & 0.004 \\
\hline \multirow[t]{3}{*}{$\mathrm{PCL}$} & Pre-treatment & 96 & $49.78(13.99)$ & 96 & $49.86(13.66)$ & & \\
\hline & Post-treatment & 61 & $39.90(15.89)$ & 63 & $42.35(15.73)$ & $-2.69(-8.08$ to 2.70$)$ & 0.32 \\
\hline & Follow-up & 61 & $32.93(14.21)$ & 64 & $39.08(15.75)$ & $-5.39(-10.76$ to -0.02$)$ & 0.05 \\
\hline \multirow[t]{3}{*}{ PHQ } & Pre-treatment & 96 & $15.09(5.17)$ & 96 & $15.04(4.99)$ & & \\
\hline & Post-treatment & 53 & $9.79(6.71)$ & 54 & $11.76(6.51)$ & $-2.18(-4.65$ to 0.29$)$ & 0.08 \\
\hline & Follow-up & 61 & $7.16(6.23)$ & 63 & $10.29(6.79)$ & $-2.91(-5.22$ to -0.60$)$ & 0.01 \\
\hline \multirow[t]{3}{*}{ Days of these difficulties present } & Pre-treatment & 92 & $20.93(9.61)$ & 93 & $20.89(8.51)$ & & \\
\hline & Post-treatment & 66 & $13.98(10.45)$ & 67 & $18.10(10.21)$ & $-3.93(-7.44$ to -0.43$)$ & 0.03 \\
\hline & Follow-up & 60 & $13.88(11.17)$ & 64 & $16.67(9.59)$ & $-2.80(-6.40$ to 0.80$)$ & 0.13 \\
\hline \multirow[t]{3}{*}{ Days of total disability } & Pre-treatment & 91 & $11.22(9.78)$ & 92 & $10.82(9.47)$ & & \\
\hline & Post-treatment & 65 & $5.03(7.15)$ & 67 & $7.82(9.03)$ & $-2.62(-5.29$ to 0.06$)$ & 0.06 \\
\hline & Follow-up & 60 & $5.82(7.34)$ & 64 & $8.00(7.82)$ & $-1.71(-4.46$ to 1.03$)$ & 0.22 \\
\hline \multirow[t]{3}{*}{ Days of activity reduce } & Pre-treatment & 90 & $14.14(10.26)$ & 92 & $12.97(10.19)$ & & \\
\hline & Post-treatment & 65 & $8.22(8.40)$ & 67 & $11.19(9.58)$ & $-2.72(-5.92$ to 0.49$)$ & 0.10 \\
\hline & Follow-up & 60 & $8.35(9.57)$ & 64 & $10.20(9.69)$ & $-1.92(-5.22$ to 1.38$))$ & 0.25 \\
\hline \multirow[t]{3}{*}{ Perceived social support } & Pre-treatment & 96 & $51.92(16.60)$ & 96 & $52.74(17.11)$ & & \\
\hline & Post-treatment & 73 & $55.53(17.70)$ & 74 & $51.43(18.03)$ & $3.85(-4.55$ to 9.25$)$ & 0.16 \\
\hline & Follow-up & 61 & $56.61(17.35)$ & 65 & $52.57(14.70)$ & $2.24(-3.42$ to 7.90$)$ & 0.43 \\
\hline \multirow[t]{3}{*}{ PSYCHLOPS } & Pre-treatment & 96 & $15.39(3.65)$ & 95 & $14.94(3.77)$ & & \\
\hline & Post-treatment & 67 & $9.31(5.68)$ & 69 & $11.55(5.01)$ & $-2.40(-4.19$ to -0.60$)$ & 0.009 \\
\hline & Follow-up & 61 & $8.98(5.93)$ & 61 & $10.62(4.99)$ & $-1.63(-3.51$ to 0.24$)$ & 0.09 \\
\hline
\end{tabular}

TAU Treatment as usual, PM + Problem Management Plus, HADS Hospital Anxiety and Depression Scales (subscale score range: 0-21; higher scores indicate elevated anxiety or depression, respectively), WHODAS WHO Disability Adjustment Scale (total score range: 0-48; higher scores indicate more severe impairment), $P C L$ Posttraumatic Stress Disorder Checklist (total score range: 17-85; higher scores indicate more severe PTSD severity), PHQ Patient Health Questionnaire (total score range: $0-27$; higher scores indicate more severe depression, PSYCHLOPS Psychological Outcome Profiles (total score range: $0-20$; higher scores indicate poorer outcome)

Post-treatment $=7$-week after baseline; Follow-up $=20$ weeks after baseline

seek to ameliorate the symptoms of anxiety and depression [13]. It has been evaluated with adults affected by adversity and experiencing psychological distress in a number of studies conducted in low resource contexts and settings, globally $[9,10,14,24]$. The results of the current study demonstrate that low intensity psychological intervention delivered by non-specialists, can improve the symptoms of anxiety and depression among adults in a specialist mental health care facility.

A key strength of the current study is that, we compared two active interventions for treatment of CMDs in a specialist mental health care facility in Pakistan $(\mathrm{PM}+$ plus routine care versus routine care alone). The results demonstrated noticeable gains in the treatment 
Table 4 Summary results from post hoc mixed-model analysis of primary and secondary outcomes, with baseline measurement (i.e. age, gender, HADS) included as covariate

\begin{tabular}{|c|c|c|c|}
\hline Primary and secondary outcomes & Visit & $\begin{array}{l}\text { Difference in least squares mean for intervention vs } \\
\text { treatment as usual }(95 \% \mathrm{Cl})\end{array}$ & $P$ value \\
\hline \multirow[t]{3}{*}{ HADS Anxiety } & Pre-treatment & & \\
\hline & Post-treatment & $-2.67(-4.32$ to -1.03$)$ & 0.002 \\
\hline & Follow-up & $-1.84(-3.56$ to -0.13$)$ & 0.04 \\
\hline \multirow[t]{3}{*}{ HADS Depression } & Pre-treatment & & \\
\hline & Post-treatment & $-1.98(-3.41$ to -0.55$)$ & 0.007 \\
\hline & Follow-up & $-1.43(-2.92$ to 0.07$)$ & 0.06 \\
\hline \multirow[t]{3}{*}{ HADS } & Pre-treatment & & \\
\hline & Post-treatment & $-4.65(-7.27$ to -2.03$)$ & 0.0006 \\
\hline & Follow-up & $-3.20(-5.92$ to -0.48$)$ & 0.02 \\
\hline \multirow[t]{3}{*}{ WHO DAS } & Pre-treatment & & \\
\hline & Post-treatment & $-3.81(-6.59$ to -1.04$)$ & 0.008 \\
\hline & Follow-up & $-4.44(-7.34$ to -1.55$)$ & 0.003 \\
\hline \multirow[t]{3}{*}{$P C L$} & Pre-treatment & & \\
\hline & Post-treatment & $-3.30(-8.71$ to 2.12$)$ & 0.23 \\
\hline & Follow-up & $-5.17(-11.08$ to -0.33$)$ & 0.04 \\
\hline \multirow[t]{3}{*}{ PHQ } & Pre-treatment & & \\
\hline & Post-treatment & $-2.51(-4.96$ to -0.06$)$ & 0.04 \\
\hline & Follow-up & $-3.04(-5.32$ to -0.76$)$ & 0.01 \\
\hline \multirow[t]{3}{*}{ Days of these difficulties present } & Pre-treatment & & \\
\hline & Post-treatment & $-4.33(-7.90$ to -0.77$)$ & 0.02 \\
\hline & Follow-up & $-2.84(-6.47$ to 0.79$)$ & 0.12 \\
\hline \multirow[t]{3}{*}{ Days of total disability } & Pre-treatment & & \\
\hline & Post-treatment & -2.51 ( -5.18 to 0.15$)$ & 0.06 \\
\hline & Follow-up & -1.69 ( -4.41 to 1.02$)$ & 0.22 \\
\hline \multirow[t]{3}{*}{ Days of activity reduce } & Pre-treatment & & \\
\hline & Post-treatment & $-3.15(-6.41$ to 0.10$)$ & 0.06 \\
\hline & Follow-up & $-1.95(-5.27$ to 1.37$)$ & 0.25 \\
\hline \multirow[t]{3}{*}{ Perceived social support } & Pre-treatment & & \\
\hline & Post-treatment & $4.45(-1.05$ to 9.95$)$ & 0.11 \\
\hline & Follow-up & $2.52(-3.22$ to 8.27$)$ & 0.39 \\
\hline \multirow[t]{3}{*}{ PSYCHLOPS } & Pre-treatment & & \\
\hline & Post-treatment & $-2.58(-4.39$ to -0.77$)$ & 0.006 \\
\hline & Follow-up & $-1.66(-3.54$ to 0.23$)$ & 0.08 \\
\hline
\end{tabular}

HADS Hospital Anxiety and Depression Scale, WHODAS WHO Disability Assessment Schedule 2.0, PCL Post-traumatic stress disorder checklist, $P H Q$ Patient Health Questionnaire, PSYCHLOPS Psychological Outcome Profile

Post-treatment $=7$-week after baseline; Follow-up $=20$ weeks after baseline

of anxiety and depression symptoms with addition of $\mathrm{PM}+$ to ongoing routine care that consisted of pharmacotherapy in most cases. The findings of our study are consistent with a systematic review and meta-analysis of literature by Cuijpers et al. [11], which concluded that pharmacotherapy and psychotherapy both contribute equally and independently to the effects of combined treatment. Hence, PM + may be a feasible and effective treatment option in outpatient psychiatry departments in LMICs, especially, where there are currently no defined psychological interventions available. However, further studies with placebo and combined pharmacotherapy and psychotherapy may be designed to understand the clinical advantage of combined treatment with $\mathrm{PM}+$ intervention in tertiary care facilities.

Another strength of this study is the finding that nonspecialists can effectively deliver the $\mathrm{PM}+$ intervention to improve treatment outcomes for CMDs in a specialist mental health care facility in Pakistan. There is an urgent need to expand the mental health care workforce to meet 
the ever-increasing demand for evidence-based, holistic mental health services in low resource settings. Our study demonstrates that trans-diagnostic psychological intervention for CMDs can be delivered by non-specialists such as psychology graduates, in outpatient psychiatry departments of low resource settings. Other studies in global mental health literature have reported similar findings where nurses, community health workers and peer volunteers have effectively delivered low intensity psychological interventions in low resource settings $[6,8$, 9, 36-39].

It may be expected that the study participants at the tertiary care facility in the current study would have more severe depression and anxiety symptoms than the participants with the CMDs from community samples. Yet, the participants in both study arms had baseline scores on symptoms of anxiety and depression similar to the other studies $[9,10,14]$ that have evaluated the effectiveness of $\mathrm{PM}+$ intervention in primary care and community settings; the drop in the symptoms scores on HADS in the present study as a result of intervention is comparatively less. These observations may be explained by (a) reported high prevalence rates of psychological distress in humanitarian settings $[4,5,40]$; (b) regression to mean phenomena. Natural remission seems to be more frequent in mild and moderate cases of depression [1, 37, 41]; and (c) exclusion of patients with severe symptoms of CMDs and in need of in-patient care from the present study.

\section{Limitations}

This study demonstrates that the addition of $\mathrm{PM}+$ intervention to routine care resulted in better treatment outcomes. However, there are a number of limitations which should be borne in mind when interpreting the study findings. First, we were able to follow only $67 \%$ of the sample at 20 weeks after baseline. This high dropout rate is expected in public mental health facilities and was accounted for in sample size calculations. Second, while the literature reports long term gains of combined treatment, we were able to follow-up patients for only 20 weeks. Third, we collected data on the use of psychotropic medicines using the CSRI, which may be subject to recall bias of study participants. Further studies may benefit from including larger sample size, longer term follow-up and objective data on the use of psychotropic medications (such as an audit of hospital medical records). Lastly, the mean number of sessions attended by participants in the intervention arm was 2.86. Although, this is in keeping with compliance rates observed in the psychiatric outpatient department in public mental health facilities in low resource settings, this may raise concerns about the adequacy of the dose of intervention received by the trial participants. A meta-regression analysis conducted by Cuijpers et al. (2013) observed a small correlation between number of therapy sessions and treatment effects and this association was not significant when the analysis adjusted for other characteristics of the studies [42]. This evidence suggests that even few but meaningful clinical interactions can benefit symptom improvement in patients with CMDs.

\section{Conclusions}

Results of the study demonstrate that the addition of $\mathrm{PM}+$ intervention to routine care resulted in better treatment outcome for the symptoms of anxiety and depression and improved functioning among outpatient attendees of a specialized mental health care facility in Pakistan. Specialized care facilities in LMICs may consider adding brief, evidence-based psychological treatments for CMDs to their routine care.

\section{Abbreviations}

CBT: Cognitive Behavioral Therapy; CMDs: Common Mental Disorders; CSRI: Client Service Receipt Inventory; GHQ-12: General Health Questionnaire-12; HADS: Hospital Anxiety and Depression Scale; IoP: Institute of Psychiatry (IoP); ITT: Intent-To-Treat; LMICs: Low and middle-income countries; MSPSS: Multidimensional Scale of Perceived Social Support; PCL-C: PTSD Checklist-Civilian version; PHQ-9: Patient Health Questionnaire; PM + : Problem Management Plus; PSYCHLOPS: Psychological Outcome Profiles instrument; PTSD: Posttraumatic Stress Disorder; RCT: Randomized Controlled Trial; TAU: TreatmentAs-Usual; WHO: World Health Organization; WHODAS 2.0: WHO Disability Assessment Schedule 2.0.

\section{Acknowledgements}

We thank the staff at the Institute of Psychiatry (loP), WHO Collaborating Centre for Mental health research and training, Rawalpindi, Pakistan, for their support in the conduct of the study, and the participants and their families for their voluntary participation.

\section{Authors' contributors}

SUH, ZeH, DW had full access to all of the data in the study and take responsibility for the integrity of the data and the accuracy of the data analysis. SUH, AR, FAM, MoV, conceived the study. SUH, ZeH, AM, ZH, HN, HA, KZ, DW, RB, MoV were involved in acquisition, analysis, or interpretation of data. SUH, ZeH, AR and MoV drafted the manuscript. All authors were involved in drafting and commenting on the trial protocol. All authors read and approved the final manuscript.

\section{Authors' information}

The authors alone are responsible for the views expressed in this article, which do not necessarily represent the views, decisions or policies of the institutions with which they are affiliated.

\section{Funding}

The study was funded by World Health Organization (WHO), Department of Mental Health and Substance Abuse, Geneva, Switzerland and Human Development Research Foundation, Pakistan (HDRF).

\section{Availability of data and materials}

The dataset generated and analyzed during the current study are available from the corresponding author on reasonable request.

\section{Ethics approval and consent to participate}

The ethical approval for the present study was obtained by Research and Ethical Committee, Rawalpindi Medical College and Allied Hospitals, Rawalpindi, Pakistan. Approval obtained on June 1, 2015. 


\section{Consent for publication}

The consent for publication was obtained from all study participants at the time of enrollment.

\section{Competing interests}

The authors declare that they have no competing interests.

\section{Author details}

${ }^{1}$ University of Liverpool, Liverpool, UK. ${ }^{2}$ Human Development Research Foundation, Islamabad, Pakistan. ${ }^{3}$ Liverpool School of Tropical Medicine, Liverpool, UK. ${ }^{4}$ Institute of Psychiatry, WHO Collaborating Center for Mental Health Research and Training, Rawalpindi, Pakistan. ${ }^{5}$ University of New South Wales, Sydney, Australia. ${ }^{6}$ World Health Organization, Geneva, Switzerland.

\section{Received: 30 April 2020 Accepted: 30 December 2020}

Published online: 19 January 2021

\section{References}

1. Whiteford H, Harris M, McKeon G, Baxter A, Pennell C, Barendregt J, et al. Estimating remission from untreated major depression: a systematic review and meta-analysis. J Psychol Med. 2013;43(8):1569-85.

2. Thornicroft G, Chatterji S, Evans-Lacko S, Gruber M, Sampson N, AguilarGaxiola S, et al. Undertreatment of people with major depressive disorder in 21 countries. Br J Psychiatry. 2017;210(2):119-24.

3. Patel V, Chisholm D, Parikh R, Charlson FJ, Degenhardt L, Dua T, et al. Addressing the burden of mental, neurological, and substance use disorders: key messages from Disease Control Priorities. Lancet. 2016;387(10028):1672-85.

4. Husain N, Chaudhry I, Afridi MA, Tomenson B, Creed F. Life stress and depression in a tribal area of Pakistan. The British Journal of Psychiatry. 2007;190(1):36-41.

5. Khan MN, Chiumento A, Dherani M, Bristow K, Sikander S, Rahman A. Psychological distress and its associations with past events in pregnant women affected by armed conflict in Swat, Pakistan: a cross sectional study. Conflict Health. 2015;9(1):37.

6. Chibanda D, Weiss HA, Verhey R, Simms V, Munjoma R, Rusakaniko S, et al. Effect of a primary care-based psychological intervention on symptoms of common mental disorders in Zimbabwe: a randomized clinical trial. JAMA. 2016;316(24):2618-26.

7. Patel V, Weobong B, Weiss HA, Anand A, Bhat B, Katti B, et al. The Healthy Activity Program (HAP), a lay counsellor-delivered brief psychological treatment for severe depression, in primary care in India: a randomised controlled trial. Lancet. 2017;389(10065):176-85.

8. Bolton P, Bass J, Neugebauer R, Verdeli H, Clougherty KF, Wickramaratne $\mathrm{P}$ et al. Group interpersonal psychotherapy for depression in rural Uganda: a randomized controlled trial. JAMA. 2003;289(23):3117-24.

9. Rahman A, Hamdani SU, Awan NR, Bryant RA, Dawson KS, Khan MF, et al. Effect of a multicomponent behavioral intervention in adults impaired by psychological distress in a conflict-affected area of Pakistan: a randomized clinical trial. JAMA. 2016;316(24):2609-17.

10. Rahman A, Khan MN, Hamdani SU, Chiumento A, Akhtar P, Nazir H, et al. Effectiveness of a brief group psychological intervention for women in a post-conflict setting in Pakistan: a single-blind, cluster, randomised controlled trial. Lancet. 2019;393(10182):1733-44.

11. Cuijpers P, Sijbrandij M, Koole SL, Andersson G, Beekman AT, Reynolds CF III. Adding psychotherapy to antidepressant medication in depression and anxiety disorders: a meta-analysis. World Psychiatry. 2014;12(3):347-58.

12. Dua T, Barbui C, Patel AA, Tablante EC, Thornicroft G, Saxena S. Discussion of the updated WHO recommendations for mental, neurological, and substance use disorders. Lancet Psychiatry. 2016;3(11):1008-12.

13. Dawson KS, Bryant RA, Harper M, Kuowei Tay A, Rahman A, Schafer A, et al. Problem Management Plus (PM+): a WHO transdiagnostic psychological intervention for common mental health problems. World Psychiatry. 2015;14(3):354-7.

14. Bryant RA, Schafer A, Dawson KS, Anjuri D, Mulili C, Ndogoni L, et al. Effectiveness of a brief behavioural intervention on psychological distress among women with a history of gender-based violence in urban Kenya: A randomised clinical trial. PLoS Med. 2017;14(8):e1002371.
15. Shah S, Van den Bergh R, Van Bellinghen B, Severy N, Sadiq S, Afridi SA, Akhtar A, Maïkére J, Van Overloop C, Khilji TB, van Griensven J. Offering mental health services in a conflict affected region of Pakistan: who comes, and why? PLoS One. 2014;9(6):e97939.

16. Hamdani SU, Ahmed Z, Sijbrandij M, Nazir H, Masood A, Akhtar P, et al. Problem Management Plus (PM+) in the management of common mental disorders in a specialized mental healthcare facility in Pakistan; study protocol for a randomized controlled trial. J Int J Mental Health Syst. 2017;11(1):40.

17. Goldberg D, Williams P, Williams P. A User's Guide to the General Health Questionnaire the General Health Questionnaire. Windsor: NFER^ Nelson Windsor: NFER^ Nelson. 1988.

18. Minhas F, Mubbashar M. Validation of General Health Questionnaire (GHQ-12) in primary care settings of Pakistan. J Coll Phys Surg Pakistan. 1996;6:133-6.

19. Üstün TB. Measuring health and disability: Manual for WHO disability assessment schedule WHODAS 2.0: World Health Organization; 2010.

20. Mumford D, Tareen I, Bajwa M, Bhatti M, Karim R. The translation and evaluation of an Urdu version of the Hospital Anxiety and Depression Scale. Acta Psychiatr Scand. 1991;83(2):81-5.

21. Zigmond AS, Snaith RP. The hospital anxiety and depression scale. Acta Psychiatr Scand. 1983;67(6):361-70.

22. World Health Organization. Measuring health and disability: manual for WHO disability assessment schedule WHODAS 2.0. . Geneva2010.

23. Federici S, Bracalenti M, Meloni F, Luciano JV. World Health Organization disability assessment schedule 2.0: an international systematic review. Disability Rehab. 2017:39(23):2347-80.

24. Khan MN, Hamdani SU, Chiumento A, Dawson K, Bryant RA, Sijbrandij $\mathrm{M}$, et al. Evaluating feasibility and acceptability of a group WHO transdiagnostic intervention for women with common mental disorders in rural Pakistan: a cluster randomised controlled feasibility trial. Epidemiol Psychiatr Sci. 2019;28(1):77-87.

25. Kroenke K, Spitzer R, Williams J. The PHQ-9: Validity of a brief depression severity measure. J Gen Intern Med. 2001;16:606-13.

26. Husain N, Gater R, Tomenson B, Creed F. Comparison of the personal health questionnaire and the self reporting questionnaire in rural Pakistan. J Pak Med Assoc. 2006;56(8):366.

27. Ahmer S, Faruqui RA, Aijaz A. Psychiatric rating scales in Urdu: a systematic review. BMC Psychiatry. 2007;7(1):59.

28. Khalily MT, Gul S, Mushtaq R, Jahangir SF. To examine delayed PTSD symptomatology over time among trauma survivors in Pakistan. Online J Counsel Educ. 2012;1(1):1-11.

29. Ashworth M, Shepherd M, Christey J, Matthews V, Wright K, Parmentier H, et al. A client-generated psychometric instrument: The development of 'PSYCHLOPS.' Counsel Psychother Res. 2004;4(2):27-31.

30. Czachowski S, Seed P, Schofield P, Ashworth M. Measuring psychological change during cognitive behaviour therapy in primary care: a polish study using 'PSYCHLOPS'(psychological outcome profiles). PLOS ONE. 2011;6(12):e27378.

31. Héðinsson H, Kristjánsdóttir H, Ólason DP, Sigurðsson JF. A validation and replication study of the patient-generated measure PSYCHLOPS on an Icelandic clinical population. Eur J Psychol Assess. 2013.

32. Zimet GD, Dahlem NW, Zimet SG, Farley GK. The multidimensional scale of perceived social support. J Pers Assess. 1988;52(1):30-41.

33. Akhtar A, Rahman A, Husain M, Chaudhry IB, Duddu V, Husain N. Multidimensional scale of perceived social support: psychometric properties in a South Asian population. J Obst Gynaecol Res. 2010;36(4):845-51.

34. Chisholm D, Knapp MRJ, Knudsen HC, Amaddeo F, Gaite L, Van Wijngaarden B. Client Socio-Demographic and Service Receipt InventoryEuropean Version: development of an instrument for international research. Br J Psychiatry. 2000;177(39):s28-33.

35. Buttorff C, Hock RS, Weiss HA, Naik S, Araya R, Kirkwood BR, et al. Economic evaluation of a task-shifting intervention for common mental disorders in India. Bull World Health Organ. 2012;90(11):813-21.

36. Naeem F, Gul M, Irfan M, Munshi T, Asif A, Rashid S, et al. Brief culturally adapted CBT (CaCBT) for depression: a randomized controlled trial from Pakistan. J Affect Disord. 2015;177:101-7.

37. Sikander S, Ahmad I, Atif N, Zaidi A, Vanobberghen F, Weiss H, et al. Delivering the Thinking Healthy Programme for perinatal depression through volunteer peers: a cluster randomised controlled trial in Pakistan. Lancet Psychiatry. 2019;6:128-39. 
38. Patel V, Weiss HA, Chowdhary N, Naik S, Pednekar S, Chatterjee S, et al. Effectiveness of an intervention led by lay health counsellors for depressive and anxiety disorders in primary care in Goa, India (MANAS): a cluster randomised controlled trial. The Lancet. 2010;376(9758):2086-95.

39. Murray LK, Familiar I, Skavenski S, Jere E, Cohen J, Imasiku M, et al. An evaluation of trauma focused cognitive behavioral therapy for children in Zambia. Child Abuse Negl. 2013;37(12):1175-85.

40. Steel Z, Chey T, Silove D, Marnane C, Bryant RA, Van Ommeren M. Association of torture and other potentially traumatic events with mental health outcomes among populations exposed to mass conflict and displacement: a systematic review and meta-analysis. JAMA. 2009;302(5):537-49.
41. Posternak MA, Miller I. Untreated short-term course of major depression: a meta-analysis of outcomes from studies using wait-list control groups. J Affect Disord. 2001;66(2-3):139-46.

42. Cuijpers P, Huibers M, Ebert DD, Koole SL, Andersson G. How much psychotherapy is needed to treat depression? A metaregression analysis. J Affect Disord. 2013;149(1-3):1-13.

\section{Publisher's Note}

Springer Nature remains neutral with regard to jurisdictional claims in published maps and institutional affiliations.
Ready to submit your research? Choose BMC and benefit from:

- fast, convenient online submission

- thorough peer review by experienced researchers in your field

- rapid publication on acceptance

- support for research data, including large and complex data types

- gold Open Access which fosters wider collaboration and increased citations

- maximum visibility for your research: over 100M website views per year

At BMC, research is always in progress.

Learn more biomedcentral.com/submissions 